\title{
Triple correlation for detection of damage-related nonlinearities in composite structures
}

\author{
A. Klepka - M. Strączkiewicz • L. Pieczonka • \\ W. J. Staszewski · L. Gelman • F. Aymerich • \\ T. Uhl
}

Received: 16 April 2014 / Accepted: 24 February 2015 / Published online: 12 March 2015

(C) The Author(s) 2015. This article is published with open access at Springerlink.com

\begin{abstract}
Nonlinear effects in vibration responses are investigated for the undamaged composite plate and the composite plate with a delamination. The analysis is focused on higher harmonic generation in vibration responses for various excitation amplitude levels. This effect is investigated using the triple correlation technique. The dynamics of composite plate was modelled using two-dimensional finite elements and the classical lamination theory. The doubled-node approach was used to model delamination area. Mode shapes and natural frequencies were estimated based on numerical models. Next, the delamination divergence analysis was used to obtain relative displacements for delaminated plies. Experimental modal analysis test was carried out to verify the numerical models. The two strongest vibration modes as well as two vibration modes with the smallest and largest motion level of delaminated plies were selected for nonlinear vibration test. The Fisher criterion was employed to verify
\end{abstract}

A. Klepka · M. Strączkiewicz · L. Pieczonka ·

W. J. Staszewski $(\bowtie) \cdot$ T. Uhl

Department of Robotics and Mechatronics,

AGH University of Science and Technology,

Al. Mickiewicza 30, 30-059 Kraków, Poland

e-mail: w.j.staszewski@agh.edu.pl

L. Gelman

Cranfield University, Cranfield MK43 0AL, UK

\section{F. Aymerich}

Department of Mechanical, Chemical and Materials Engineering, University of Cagliari Piazza d'Armi, 09123 Cagliari, Italy the effectiveness and confidence level of the proposed technique. The results show that the method can be used not only to reveal nonlinearities, but also to reliably detect impact damage in composites. These results are confirmed using the statistical analysis.

Keywords Composites - Damage-related nonlinearities - Impact damage detection - Nonlinear vibration . Higher harmonics generation · Triple correlation

\section{Introduction}

Composite materials are widely used in many engineering applications due to their interesting properties such as low weight, fatigue strength, resistance to corrosion and design flexibility. It is well known that performance of composite structures can be significantly reduced by manufacturing defects and service-induced damage. The latter is often caused by low-velocity impacts that can lead to sub-surface, hidden damage due to layered structure of composites. This type of damage can take various forms such as matrix cracks (occurs parallel to the fibres due to compression, tension or shear), fibre breakages (due to tension), bucking (due to compression) or delamination (produced by interlaminar stress). Low-velocity impact damage modifies structural parameters and has a knockdown effect on the residual strength of composite structures. This is one of the major reasons why monitoring for possible structural damage is important in composites, as dis- 
cussed in [1]. Various methods have been developed for damage detection in composite structures. Altogether, these methods can be classified as passive and active [2]. The former includes methods based on acoustic emission [3,4], operational load monitoring [1,5] and impact detection techniques [1,6-10]. The latter covers various methods based on vibration analysis [1114] and non-destructive techniques, such X-ray [15, 16], shearography [1,17], vibro-thermography $[18,19]$, ultrasonic and acousto-ultrasonic testing [20,21], and guided ultrasonic waves [22-26]. Recent years have brought research interest in various damage-related nonlinear phenomena that can be observed in ultrasonic responses and vibration characteristics. It is usually anticipated that the sensitivity of nonlinear approaches is much better than the equivalent linear techniques.

Nonlinear acoustics methods utilise higher, super and sub-harmonic generation, frequency shifting, signal modulations, modulation transfer or hysteretic behaviour. Recent examples in the field-related to composite materials - include studies based on higher harmonics generation [27-29], nonlinear Lamb waves [30], nonlinear vibro-acoustic wave modulations [3136], non-classical, nonlinear modulation transfer [37], analysis of fast/slow dynamics [38] and bispectral analysis $[39,40]$.

It is well known that in vibration analysis, changes to natural frequencies, mode shapes, curvatures, flexibility coefficients and input-output characteristics (e.g. frequency response function, transfer function) can be used to detect structural damage, as reviewed in [11-14]. An excellent overview of vibration-based methods-that also cover nonlinear approaches-can be found in [41-43]. It is important to note that delamination detection in composites-based on vibration analysis-is a challenging task. This is mainly due to the fact that delamination in composites has no parallel to damage mechanisms in other materials [11,44]. In addition, detection of small delaminations in composite specimens is questionable, as discussed in [1]. Recent examples related to composite materials include studies of nonlinear response characteristics [45], reciprocity analysis [46,47], curvatures and mode shapes [48], modal filtering [49], nonlinear time series [50], nonlinear interactions [51] and higher-order spectra [40,52]. The latter is particularly attractive for the detection of small quadratic nonlinearities.

The paper presents the application of the novel triple correlation technique — based on the short-time Fourier transform (STFT) - for damage detection in composite structures. Monitored damaged structures are excited modally using single-input harmonic excitation. Various vibration modes and different amplitude levels of excitations are applied. The proposed higher-order statistic is employed to correlate the fundamental harmonic with higher harmonics that result from structural damage-related nonlinearities. The Fisher criterion is used to establish the optimal excitation amplitude for damage detection.

The paper starts with the theoretical background. Section 2 illustrates simple models to explain nonlinear behaviour of composite delaminated plates. The proposed triple correlation coefficient is briefly described in Sect. 3. The composite specimen used is described in Sect. 4. Numerical simulations performed to select vibration modes for the experimental nonlinear analysis are presented in Sect. 5. This work involves modal analysis and divergence analysis of delaminated plies. The latter is used to establish vibration modes that lead to dominant out-of-plane and in-plane motion of delaminated plies. Section 6 describes the entire experimental work undertaken. Intact and delaminated composite plates are used to illustrate the performance of the method. Damage detection results are presented in Sect. 7. Finally, the paper is concluded in Sect. 8.

\section{Nonlinear coupling in a composite delaminated plates: theoretical background}

Nonlinearity is a common feature in vibration characteristic of nearly all engineering structures. Vibration/modal analysis often exhibits nonlinear symptoms due to material behaviour, boundary conditions, measurement chain or structural damage. The latter is of interest in the current investigations. The physical mechanism behind various types of nonlinearities is manifold and includes global effects-such as imperfection of atomic lattices (e.g. intrinsic or material nonlinearity) - and/or local effects—such as contact interaction between structural elements or structural damage. Material nonlinearity is a subject of many investigations since the early 1960s. Various methods have been developed to detect material imperfections such as for example micro-cracks in materials. Local nonlinearity can produce nonlinear effects in the form of higher, sub- and super-harmonics, frequency mix- 
Fig. 1 Out-of-plane excitation of delamination-the stress-strain characteristic under tension and compression

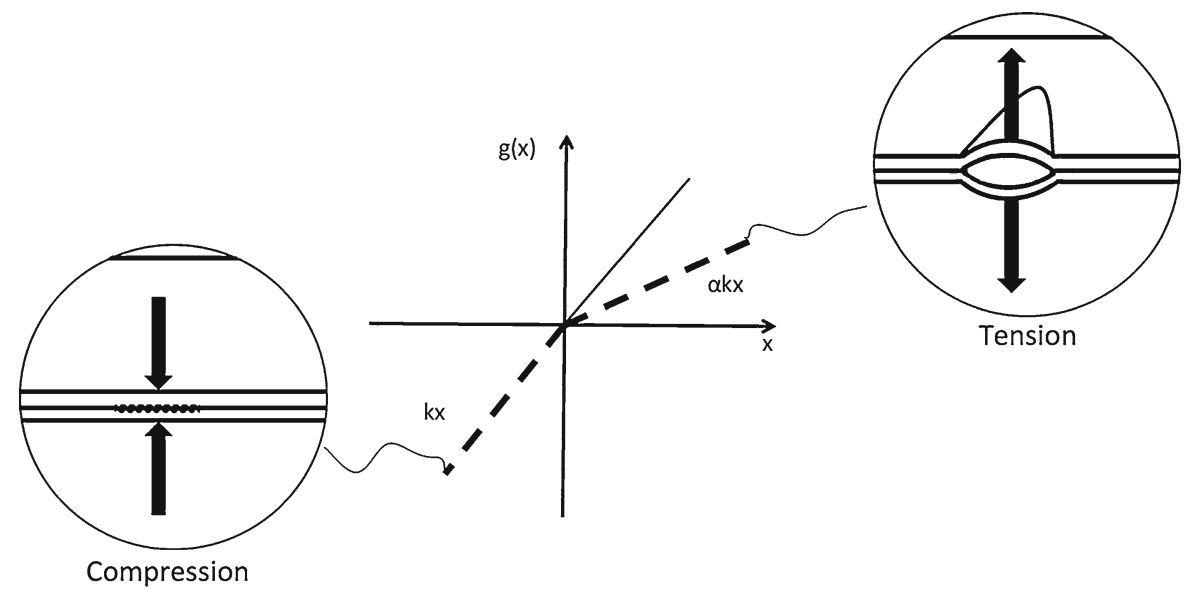

ing and shifting, modulation transfer, slow dynamics effects or reverberation, as discussed in [53].

This paper investigates the classical effect of higher harmonic generation under single harmonic excitation. This effect can be explained using a simple model of delamination based on a bilinear oscillator, as explained in $[54,55]$. It is well known that delamination leads to local stiffness reduction and modifies the stressstrain characteristics. For the out-of-plane excitation, stiffness is different under compression and tension, as illustrated in Fig. 1. A simple lumped parameter model can be used to analyse this effect. The relevant equation of motion for the analysed delamination can be given as

$$
\left\{\begin{array}{l}
m \ddot{x}+c \dot{x}+\alpha k x=F(t) \text { for } x \geq 0 \\
m \ddot{x}+c \dot{x}+k x=F(t) \text { for } x<0
\end{array}\right.
$$

where $m, c, k$ are mass, damping and stiffness parameters, respectively, $\alpha$ is a stiffness ratio $(0 \leq \alpha \leq 1)$, $F(t)=A \cos (\omega \mathrm{t})$ is the external harmonic force, and $x(t)$ is displacement. The restoring force for the bilinear oscillator-illustrated in Fig. 1 -is thus given by

$g(x)=\left\{\begin{array}{l}\alpha k x \rightarrow x \geq 0 \\ k x \rightarrow x<0\end{array}\right.$

where $g(x)$ is a piecewise linear continuous function of displacement $x$. This piecewise linear continuous function of displacement $x$ is assumed to be continuous and therefore can be approximated by a polynomial. Then the entire model can be rewritten in the form

$m \ddot{x}+c \dot{x}+K x=F(t)$

where

$K(x)=\sum_{i=1}^{n} c_{i} k x^{i}$ and $c_{i} k$ are polynomial coefficients, $n$ is a polynomial order and $i=1, \ldots, n$. The general form of Eq. (3) takes the form

$$
\begin{aligned}
& m \ddot{x}+c \dot{x}+c_{1} k x+c_{2} k x^{2}+c_{3} k x^{3} \\
& +\ldots+c_{i} k x^{i}=F(t)
\end{aligned}
$$

In case of harmonic excitation

$F(t)=A \cos \omega t=\frac{A}{2} e^{j \omega t}+\frac{A}{2} e^{-j \omega t}$

the response of the system can be expressed as [56]

$x(t)=\sum_{n=1}^{i}\left(\frac{A}{2}\right) \sum_{p+q=n}{ }^{n} C_{q} H_{n}^{p, q}(\omega) e^{j \omega_{p, q} t}$

The term $H_{n}^{p, q}(\omega)$ is the higher-order frequency response function (FRF) and can be written in form

$H_{n}^{p, q}(\omega)=H_{n}(\underbrace{\omega \ldots \ldots, \omega,}_{p \text { times }}-\underbrace{\omega \ldots \ldots, \ldots,-\omega}_{q \text { times }})$

The response amplitude of the first three harmonics can be expressed as [57]

$X(\omega)=A H_{1}(\omega)+\frac{3 A^{3}}{4} H_{3}(\omega, \omega,-\omega)+\Omega$
$X(2 \omega)=\frac{A^{2}}{2} H_{2}(\omega, \omega)+\frac{A^{2}}{2} H_{4}(\omega, \omega, \omega,-\omega)+\Omega$

$X(3 \omega)=\frac{A^{3}}{4} H_{3}(\omega, \omega, \omega)+\Omega$

where $\Omega$ indicates the higher-order terms. The higherorder FRFc can be estimated using Volterra series, based on first-order FRFs [57] 
Fig. 2 Stress-strain characteristics and wave deformation for the micro-slip mode (a, b) and the stick and slip mode (c, d)
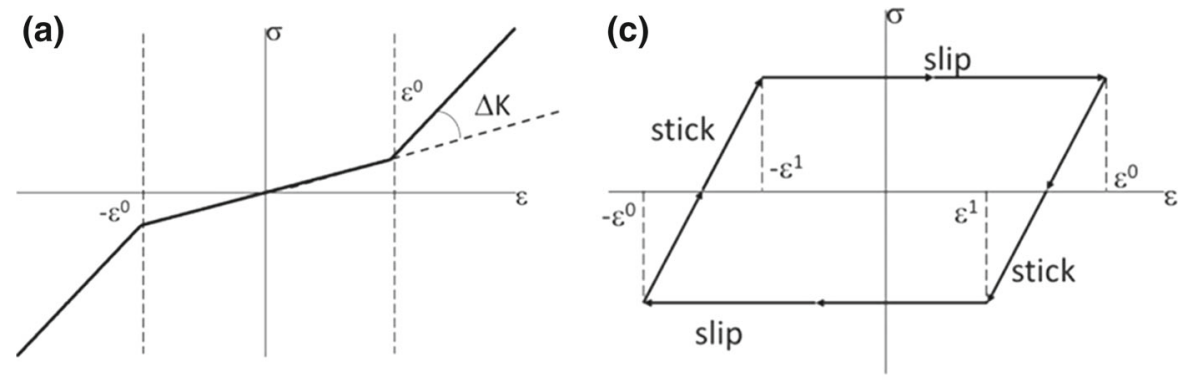

(b)

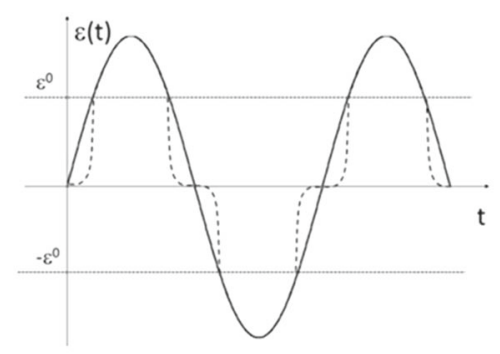

(d)

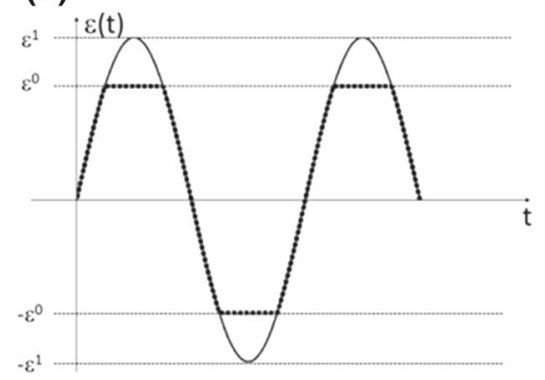

$$
\begin{aligned}
& H_{2}(\omega, \omega)=-c_{2} k H_{1}^{2}(\omega) * H_{1}(2 \omega) \\
& H_{3}(\omega, \omega, \omega)=H_{1}^{3}(\omega) * H_{1}(3 \omega) \\
& \quad *\left\lfloor 2\left(c_{2} k\right)^{2} H_{1}(2 \omega)-c_{3} k\right\rfloor
\end{aligned}
$$

In the case of in-plane motion, a more complex model can be assumed. Any mechanical connection of delaminated plies is caused by friction forces. If the amplitude of excitation is low, delaminated plies are displaced in a micro-slip mode between neighbouring rough areas. This displacement-independent of motion direction - changes the stiffness characteristics twice (symmetrical nonlinearity). In this case, only odd harmonics are generated. When the amplitude of excitation increases enough, the contact static friction forces become broken. Then delaminated plies start sliding in a stick and slip mode. This means that firstly the asperities - coupled by adhesion force-deform elastically and then plastically (slip). This causes a cyclic change between static and kinematic friction phases, which turn the strain-stress characteristic into a hysteresis. As in the case of micro-slip mode, the changes are independent of displacement direction and change stiffness twice per one cycle of loading, causing generation of only odd harmonics. Figure 2 illustrates stress-strain characteristics for the micro-slip and the stick and slip modes.

Simple models presented in this section are sufficient to explain the process of higher harmonics gen- eration. It is important to note that other models—such are asymmetrical dynamic fracture [57], bifurcation [58], discontinuities [59] or contact interaction [60] models - can be also used to explain the physics of investigated nonlinear phenomena. In practice, dynamic behaviour of damaged delaminated plate is much more complicated. A good example of multiple delamination dynamics-based on analytic modelling — is given in [61].

\section{Triple correlation coefficient based on the short-time Fourier transform}

The triple correlation (TC) was firstly investigated in the early 1960 s to examine non-Gaussian random processes. The early applications of the technique includes statistical examining of laser spectroscopy and ocean waves [62,63], fatigue and condition [64,65] monitoring. The triple correlation is somehow less popular than the standard (i.e. doubled) correlation and is mainly used when multiple observations-embedded in additive noise and corrupted by trends-are present in analysed signals.

In general form, the auto-triple correlation can be defined as

$c\left(\tau_{1}, \tau_{2}\right)=\int x(t) x\left(t+\tau_{1}\right) x\left(t+\tau_{2}\right) \mathrm{dt}$

where $x(t)$ is a time domain signal and $\tau_{1}$ and $\tau_{2}$ are time delay intervals. For zero values of $\tau_{1}$ and $\tau_{2}$, the 
triple correlation is proportional to the auto-correlation function. It follows that the triple correlation contains information on both, i.e. the amplitude and phase of the signal. Therefore, original signals can be easily reconstructed. In practical application, the time delay intervals $\tau_{1}$ and $\tau_{2}$ are correlated with frequency values in the spectral domain. The Fourier transform of the auto-triple correlation is the bispectrum that can be defined as

$$
B\left(f_{1}+f_{2}\right)=X^{*}\left(f_{1}+f_{2}\right) X\left(f_{1}\right)\left(f_{2}\right)
$$

where $X(\cdot)$ is the Fourier transform of $x(\cdot)$ and "*" indicates the complex conjugate. This function is often used to search - through quadratic phase couplingsfor nonlinear interactions in signals.

The work presented in this paper relies on the triple correlation coefficient that can be used for detection and correlation of nonlinear components in analysed signal segments $[65,66]$. The procedure can be summarised as follows. The analysed signal is divided into overlapping segments. For each of the segments, the Fourier transform is computed. Then, the mean values of the relevant transforms at the suspected frequencies $f_{1}, f_{2}$ and $f_{3}=f_{1}+f_{2}$ are obtained. Finally, the unnormalised result, i.e. the triple covariance, is acquired as [65]

$$
\begin{aligned}
\operatorname{tri} \operatorname{cov}\left(f_{1}, f_{2}\right)= & \frac{1}{M} \sum_{M}\left\{X_{M}\left(f_{1}\right)-m\left[X_{M}\left(f_{1}\right)\right]\right\} \\
& \times\left\{X_{M}\left(f_{2}\right)-m\left[X_{M}\left(f_{2}\right)\right]\right. \\
& \left.\times\left\{X_{M}\left(f_{3}\right)\right\}-m\left[X_{M}\left(f_{3}\right)\right]\right\}^{*}
\end{aligned}
$$

where $X_{M}$ is the Fourier transform of the signal's M-th segment, $f_{1}$ and $f_{2}$ denote frequency values of components for which the correlation is estimated, $\mathrm{M}$ is a number of segments and $f_{3}=f_{1}+f_{2}$. Normalisation leads to the third-order statistics defined as
One can prove-using the Schwartz inequality, i.e.

$$
\left|E\left[z_{1} z_{2} z_{3}\right]\right|^{2} \leq E\left\lfloor\left|z_{1}\right|^{2}\right\rfloor E\left\lfloor\left|z_{2}\right|^{2}\right\rfloor E\left\lfloor\left|z_{3}\right|^{2}\right\rfloor
$$

where

$$
z_{1}=X_{M}\left(f_{1}\right)-m\left[X_{M}\left(f_{1}\right)\right], z_{2}=X_{M}\left(f_{2}\right)-
$$
$m\left[X_{M}\left(f_{2}\right)\right], z_{3}=X_{M}\left(f_{3}\right)-m\left[X_{M}\left(f_{3}\right)\right]$, that the obtained statistics is bounded between 0 and 1, i.e.

$0 \leq C\left(f_{1}, f_{2}\right) \leq 1$

This statistics offers a quantifiable correlation between components of analysed signals.

\section{Delaminated composite plate}

The specimen used in the current investigations was a $150 \times 300 \mathrm{~mm}$ carbon/epoxy (Seal HS160/REM) plate with unidirectional prepreg layers, shown in Fig. 3a. The stacking sequence of the laminate was $\left[0_{3} / 90_{3}\right] \mathrm{s}$. The average laminate thickness was equal to $2 \mathrm{~mm}$. The specimen was ultrasonically $\mathrm{C}$-scanned prior to testing to assess the quality of the laminate and to exclude the presence of manufacturing defects. Impact tests were conducted using an instrumented drop-weight testing machine. The composite panel was simply supported by a steel plate having a rectangular opening $45 \mathrm{~mm} \times 67.5 \mathrm{~mm}$ in size (with the longer side along the $0^{\circ}$ direction) and impacted at the centre of the opening. The impactor of the drop-weight machine had a mass of $2.3 \mathrm{~kg}$ and was equipped with a hemispherical indenter of $12.5 \mathrm{~mm}$ in diameter. The $3.9 \mathrm{~J}$ of impact energy was obtained by varying the drop height of the impactor. The absorbed energy was evaluated by measuring (using an infrared sensor) velocities of the impactor immediately before and after the impact; the contact force was measured by means of a semiconductor strain-gage bridge bonded to the indenter.

$C\left(f_{1}, f_{2}\right)=\frac{\frac{1}{M} \sum_{M}\left\{X_{M}\left(f_{1}\right)-m\left[X_{M}\left(f_{1}\right)\right]\right\}\left\{X_{M}\left(f_{2}\right)-m\left[X_{M}\left(f_{2}\right)\right]\left\{X_{M}\left(f_{3}\right)\right\}-m\left[X_{M}\left(f_{3}\right)\right]\right\}^{*}}{\sqrt{\operatorname{var}\left[X_{M}\left(f_{1}\right)\right] \operatorname{var}\left[X_{M}\left(f_{2}\right)\right]\left[X_{M}\left(f_{3}\right)\right]}}$

where $m$ denotes the symbol of the mathematical expectation. The variance var of the complex-value quantity in Eq. (15) is defined as

$$
\begin{aligned}
\operatorname{var}\left[X_{M}\left(f_{1}\right)\right]= & \frac{1}{M} \sum\left\{X_{M}\left(f_{1}\right)-m\left[X_{M}\left(f_{1}\right)\right]\right\} \\
& -\left\{X_{M}\left(f_{1}\right)-m\left[X_{M}\left(f_{1}\right)\right]\right\}^{*}
\end{aligned}
$$

The impact force characteristic is presented in Fig. 4. Ultrasonic testing was used to characterise the nature and extent of the internal damage. The $\mathrm{C}$-scan result is shown in Fig. 3b. The damage was observed between the $90^{\circ}$ and the $0^{\circ}$ plies farthest from the impact side. The area of damage was estimated as $326 \mathrm{~mm}^{2}(0.7 \%$ of the total area of the plate). 
Fig. 3 Composite plate used in damage detection tests: a general view; b ultrasonic C-scan image of centrally located delaminated area (a)

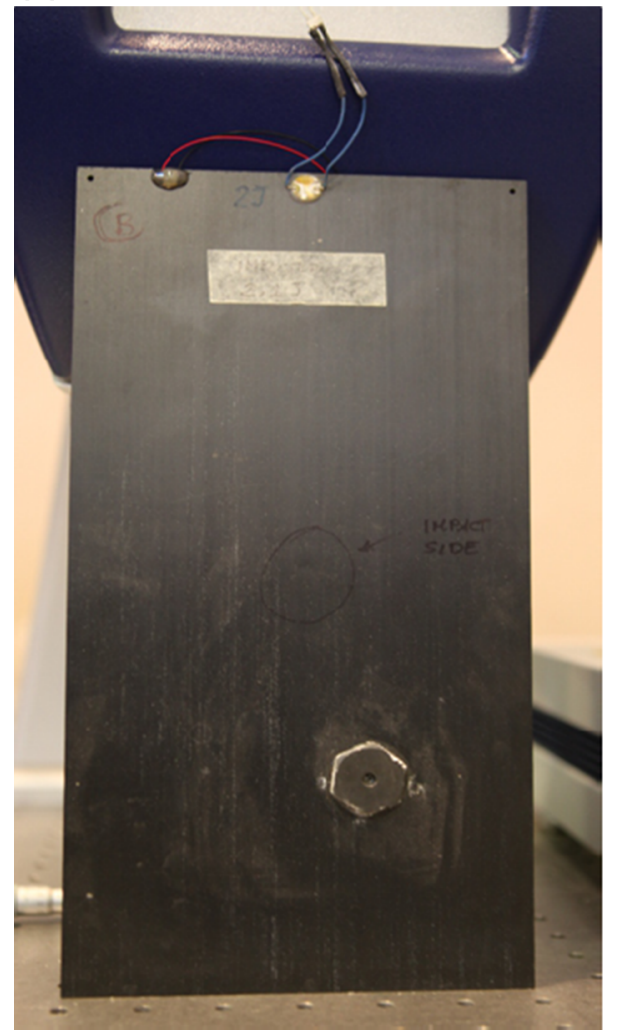

(b)

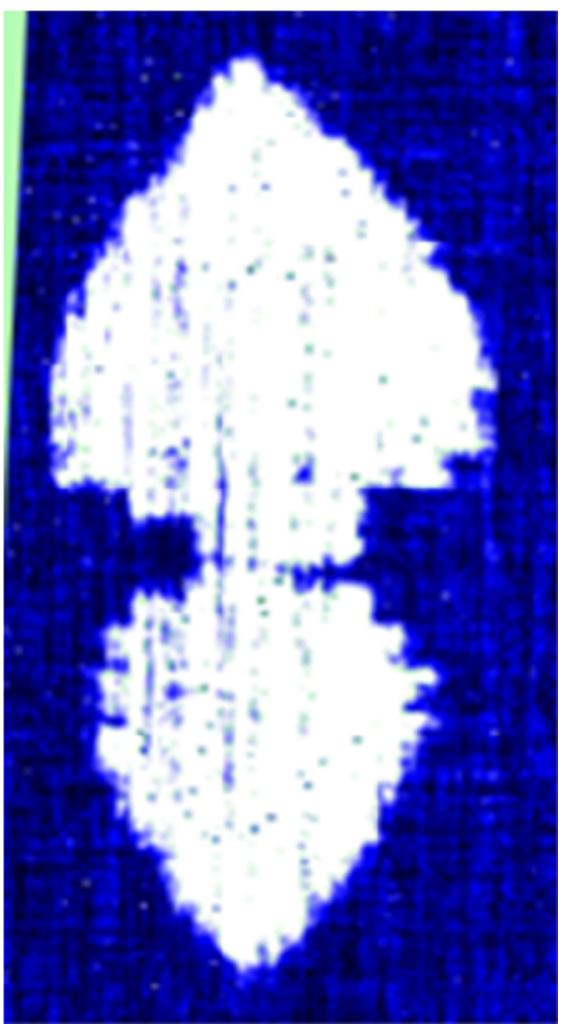

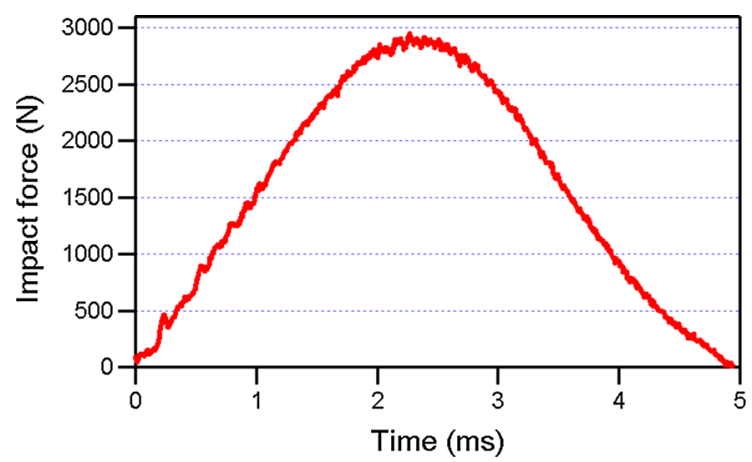

Fig. 4 Impact force characteristic

\section{Numerical simulations}

This section describes numerical simulations undertaken to analyse the divergence of delamination and the dynamics of the delaminated composite plate. Firstly, the FE model of the delaminated composite plate is briefly described. Then the divergence and modal analyses performed are explained. Numerical simula- tions were used to select vibration modes for the nonlinear vibration test described in Sect. 6.

\subsection{Finite element model of the delaminated plate}

Vibration/modal analysis of delaminated composite plates-based on numerical simulations-has been extensively studied in the past $[67,68]$. The dynamics of thin laminated composites can be effectively modelled using two-dimensional (2D) finite elements and the classical lamination theory (CLT) [69]. However, it is well known that modelling of internal delamination requires three-dimensional (3D) finite elements. When this approach is used, orthotropic material properties are applied for representation of each individual lamina. The linear stress-strain relation in the form of a compliance matrix takes the form

$\varepsilon_{i}=S_{i j} \sigma_{i j}$

where $\varepsilon_{i}=\left[\varepsilon_{1}, \varepsilon_{2}, \varepsilon_{2}, \varepsilon_{12}, \varepsilon_{13}, \varepsilon_{23}\right]^{T}$ is the vector of strains, $\sigma_{i}=\left[\sigma_{1}, \sigma_{2}, \sigma_{2}, \sigma_{12}, \sigma_{13}, \sigma_{23}\right]^{T}$ is the vector 


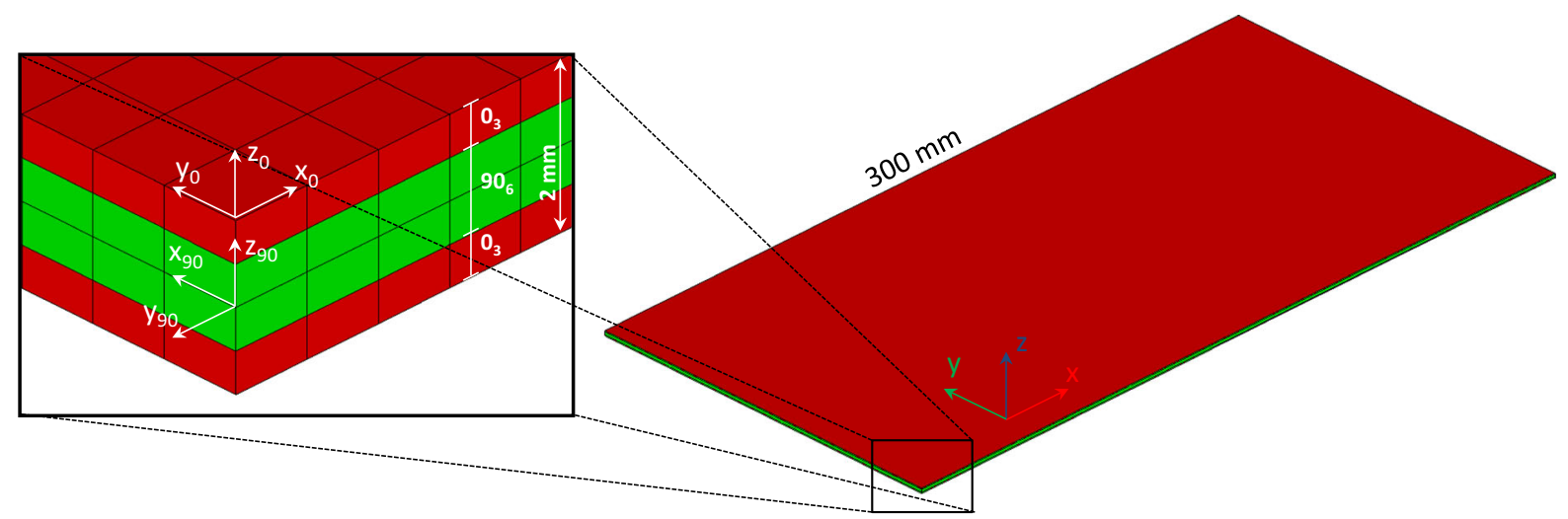

Fig. 5 Finite element model of the analysed composite plate - a general view with overall dimensions (right) and the ply stacking sequence together with the local coordinate systems (left)

of stresses, and the compliance matrix $S_{i j}$ takes the form

$$
S_{i j}=\left[\begin{array}{llllll}
\frac{1}{E_{1}} & \frac{-v_{21}}{E_{2}} & \frac{-v_{31}}{E_{3}} & 0 & 0 & 0 \\
\frac{-v_{12}}{E_{1}} & \frac{1}{E_{2}} & \frac{-v_{32}}{E_{3}} & 0 & 0 & 0 \\
\frac{-v_{13}}{E_{1}} & \frac{-v_{23}}{E_{2}} & \frac{1}{E_{3}} & 0 & 0 & 0 \\
0 & 0 & 0 & \frac{1}{G_{12}} & 0 & 0 \\
0 & 0 & 0 & 0 & \frac{1}{G_{13}} & 0 \\
0 & 0 & 0 & 0 & 0 & \frac{1}{G_{23}}
\end{array}\right]
$$

There are only 9 independent elastic constants, i.e. $E_{1}, E_{2}, E_{3}, G_{12}, G_{13}, G_{23}, v_{12}, v_{13}$ and $v_{23}$, due to the symmetry of the compliance matrix.

The delaminated composite plate-described in Sect. 4-was modelled using MSC.Patran FE preprocessor. The plate was discretised using 800000 3D linear hexahedral elements (Fig. 5). The desired ply stacking sequence- $\left[0_{3} / 90_{3}\right] \mathrm{s}-$ was reproduced using four elements across the thickness of the plate, so that each finite element represented three plies with the same orientation, as shown in Fig. 5. Two local coordinate systems were created: $\left(x_{0}, y_{0}, z_{0}\right)$ and $\left(x_{90}, y_{90}, z_{90}\right)$ to account for different ply orientations. The orthotropic material properties for the $0^{\circ}$ and $90^{\circ}$ plies were defined in these local coordinate systems.

The area of delamination was modelled using the doubled-node approach. Two distinct nodes in the same geometrical location at the delaminated interface were used. One of these nodes belonged to an element of the upper delamination face, and the other node belonged to an element of the lower delamination face, as shown in Fig. 6. As a result, neighbouring finite elements were disconnected in the desired area

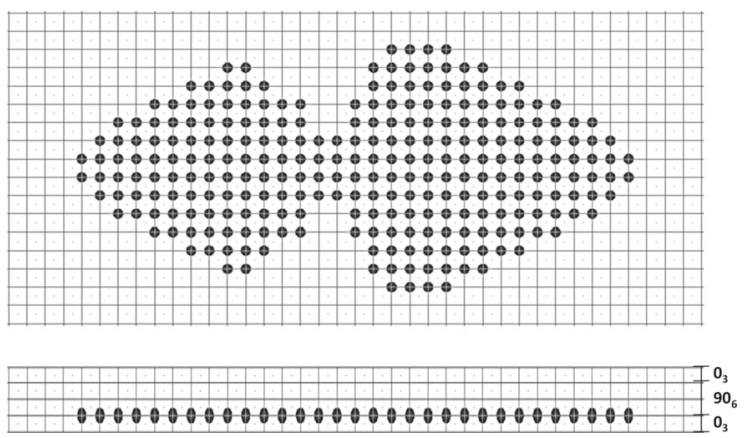

Fig. 6 Delamination modelled in the finite element mesh of the composite plate

between the $90^{\circ}$ and the $0^{\circ}$ plies that were located farthest from the impacted side. The model reproduced the location and geometry of delamination described in Sect. 4. This simplified damage model was sufficient for the delamination divergence analysis. The entire analysis involved the following material parameters: the Young's moduli: $\mathrm{E}_{1}=93.7 \mathrm{GPa}, \mathrm{E}_{2}=7.45 \mathrm{GPa}$, $\mathrm{E}_{3}=7.45 \mathrm{GPa}$; the shear moduli: $\mathrm{G}_{12}=3.97 \mathrm{GPa}$, $\mathrm{G}_{13}=3.97 \mathrm{GPa}, \mathrm{G}_{23}=3.97 \mathrm{GPa}$; the Poisson's ratios: $v_{12}=0.261, v_{13}=0.261, v_{23}=0.261$ and the density: $\rho=1.5 \mathrm{~g} / \mathrm{mm} 3$.

\subsection{Modal analysis}

Modal analysis was applied to the composite plate using numerical simulations. Natural frequencies and mode shapes can be obtained solving the free undamped vibration problem. The equations of motion for the composite plate can be formulated as 
Fig. 7 Delamination motion scenarios in a composite plate: a out-of-plane motion; $\mathbf{b}$ in-plane motion
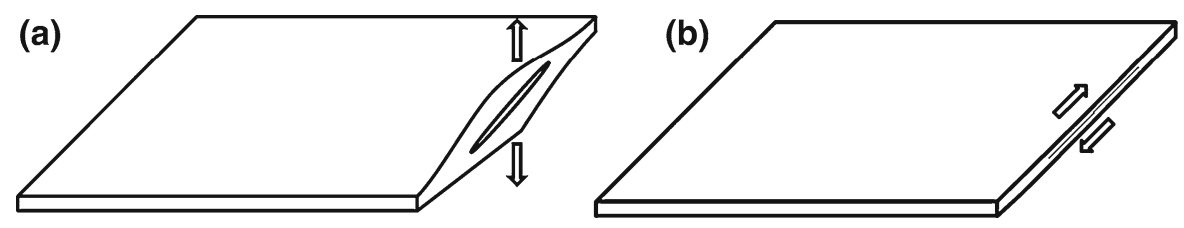

$[M]\{\ddot{u}\}+[K]\{u\}=0$

where $[M]$ is the mass matrix, $[K]$ is the stiffness matrix, $\{u\}$ is the displacements vector, $\{\ddot{u}\}$ is the accelerations vector.

Equation (21) can be solved assuming the solution of the form

$\{u\}=\{\phi\} \sin \omega t$

where $\{\phi\}$ is an eigenvector and $\omega$ is the circular natural frequency of vibration. Substituting Eqs. (22) to (21) yields

$$
-\omega^{2}[M]\{\phi\} \sin \omega t+[K]\{\phi\} \sin \omega t=0
$$

This can be rewritten in a simplified form as

$$
\left([K]-\omega^{2}[M]\right)\{\phi\}=0
$$

It is well known that the above set of equations can be satisfied when: $\{\phi\}=0$ or when $\operatorname{det}\left([K]-\omega^{2}[M]\right)$ $\{\phi\}=0$. The former is a trivial solution, representing the case when no motion occurs. The latter can be investigated to find the solutions. The determinant $\operatorname{det}\left([K]-\omega^{2}[M]\right)$ becomes zero at a discrete set of eigenvalues $\omega_{i}^{2}$ that are accompanied by the corresponding eigenvectors $\left\{\phi_{i}\right\}$. Each pair of eigenvalue and eigenvector represents a free undamped vibration mode of the plate. The frequency of vibration $f_{i}$ equals $\omega_{i} / 2 \pi$. The eigenvectors $\left\{\phi_{i}\right\}$ are mutually orthogonal, meaning that vibration mode shapes described by the eigenvectors are unique and cannot be described by a linear combination of other mode shapes. The mode shapes that are calculated are arbitrarily scaled, as there is no forcing on the right-hand side of Eq. (21). The work presented in this paper assumes the mass normalisation of eigenvectors, i.e. the eigenvectors fulfil the formula

$$
\left\{\phi_{i}\right\}[M]\left\{\phi_{i}\right\}=1
$$

There are several techniques that can be applied for the solution of an eigenproblem [70]. In the present study, the Lanczos algorithm was applied, as it is proven to accurately compute a discrete set of eigenvalues and eigenvectors for medium and large size FE models. It is also important to note that the algorithm used does not miss any roots and offers very good numerical performance [71].

The MSC.Nastran FE solver was used to perform computations. The normal modes solution (SOL103) was applied to find vibration mode shapes of the delaminated composite plate in the frequency range from 0 to $1000 \mathrm{~Hz}$.

\subsection{Delamination divergence analysis}

Delamination divergence analysis was performed using the mode shape results from modal analysis described in Sect. 5.2. It is clear that when a delaminated composite plate is excited, the dynamics of delamination is quite complex, as explained in Sect. 2. However, there are two extreme scenarios with respect to the movement of the delaminated plies. When out-of-plane motion is mainly involved, two delaminated plies are either in tension or in compression, as illustrated in Fig. 7. The former leads to a clear gap between delaminated plies (Fig. 7a). When in-plane motion is applied, two delaminated plies are in contact and sliding of delaminated plies is possible (Fig. 7b). In practice, both motions are combined together when the plate is vibrated.

The relative motion of delaminated plies was studied in the divergence analysis. This analysis was focused on all pairs of doubled nodes in the delaminated area. The relative displacement amplitude was assessed to analyse the movement of the disconnected nodes. The movement in the direction normal to the plate ( $\mathrm{z}$ coordinate) was analysed for the out-of-plane motion

$$
\left\{\delta \phi_{i}^{z}\right\}=\left|\left\{\phi_{i}^{z \_ \text {top }}\right\}-\left\{\phi_{i}^{z \_ \text {bottom }}\right\}\right|
$$

For the in-plane motion, $x$ and $y$ coordinates were analysed

$$
\left\{\delta \phi_{i}^{x y}\right\}=\sqrt{\left(\left\{\phi_{i}^{x_{-} \text {top }}\right\}-\left\{\phi_{i}^{x_{-}}{ }^{\text {bottom }}\right\}\right)^{2}+\left(\left\{\phi_{i}^{y_{-} \text {top }}\right\}-\left\{\phi_{i}^{y_{-} \text {bottom }}\right\}\right)^{2}}
$$

Then the mean value of relative displacements for the entire delaminated area was calculated to estab- 
Fig. 8 Delamination divergence analysis for the analysed vibration modes

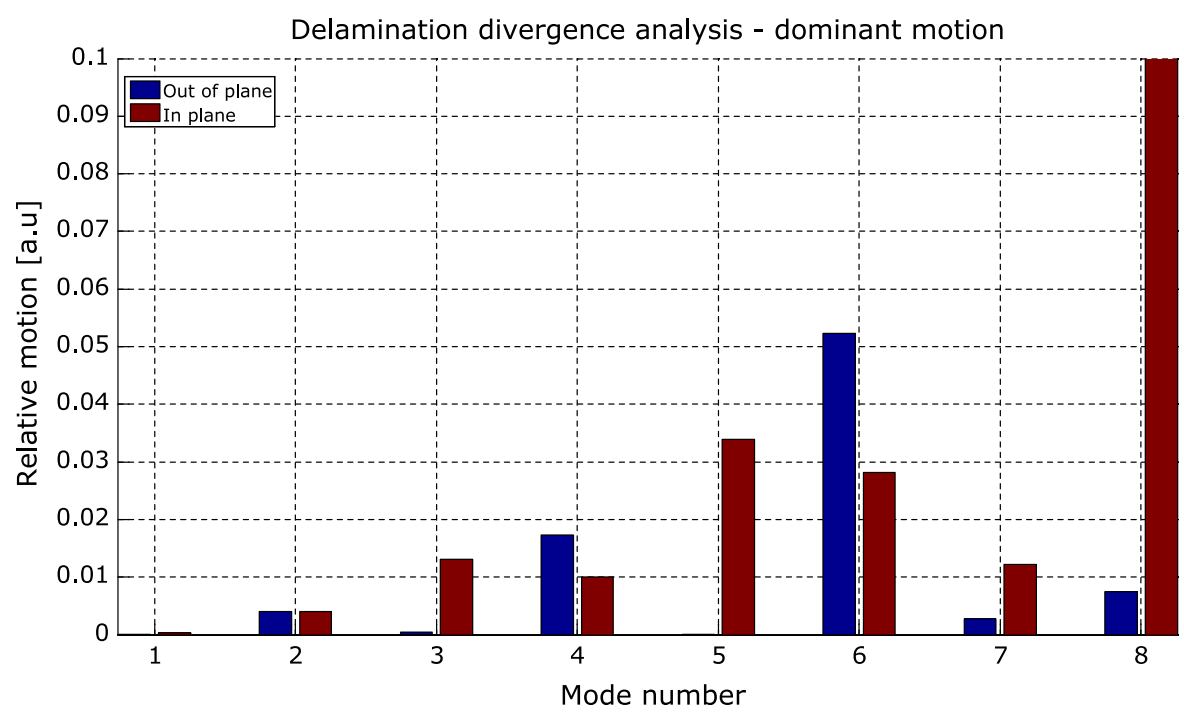

lish which movement of delaminated plies (i.e. outof-plane leading to a gap or in-plane leading to a frictional contact) is dominant for a given vibration mode excitation. The delamination divergence analysis was performed for all vibration modes involved. The results-presented in Fig. 8-demonstrate how different vibration modes contribute to different types of delamination motions (i.e. combined out-of-plane and in-plane motion). These results show that the first and eighth vibration modes lead to the smallest and largest motion of delaminated plies, respectively. The fourth and sixth vibration modes produce the dominant out-of-plane motion, whereas the remaining analysed vibration modes exhibit the dominant in-plane motion.

\section{Experimental vibration tests}

This section describes the experimental work undertaken for damage detection. Firstly, experimental modal analysis was performed. The results from modal analysis and the delamination divergence analysisdescribed in Sect. 5.3-were used to select excitation frequencies for the nonlinear vibration test. This test was performed to reveal damage-related nonlinearities.

\subsection{Experimental modal analysis}

The composite plate was suspended using elastic cords to minimise undesired effects from boundaries. White noise excitation was used in the experimental modal analysis. The excitation signal was generated using a built-in signal generator of the in Polytec PSV400 laser vibrometer and amplified by an Electronics PAHV 2000 high-voltage amplifier. The excitation was introduced to the plate through a surface-bonded NOLIAC CMAP04 stack actuator. A Polytec PSV-400 laser vibrometer was used for non-contact measurement of vibration responses.

The frequency response functions (FRFs) and vibration mode shapes were estimated from the experimental input and output data using the Polytec PSV 8.8 software. The amplitude of the FRF-presented in Fig. 9-displays a series of components corresponding to frequencies of various vibration modes illustrated in Fig. 10. The modal assurance criteria (MAC) coefficient was used to correlate these modes with the results obtained from numerical simulations. The results show that the fourth and fifth vibration modes are the strongest vibration modes investigated.

The combined results of the experimental modal analysis (Fig. 9a) and the simulated delamination divergence analysis (Fig. 8) were used to select vibration modes for excitation in the nonlinear vibration test described in Sect. 6.2. The two strongest vibration modes and the two vibration modes that lead to the smallest and largest levels of motion of delaminated plies were selected. These are:

- 1st vibration mode $(79 \mathrm{~Hz})$ - produces very little or virtually no movement of delaminated plies;

- 4th vibration mode $(334 \mathrm{~Hz})$ - the strongest vibration mode with the dominant out-of-plane motion of delaminated plies; 
Fig. 9 Experimental modal analysis results-FRF amplitude

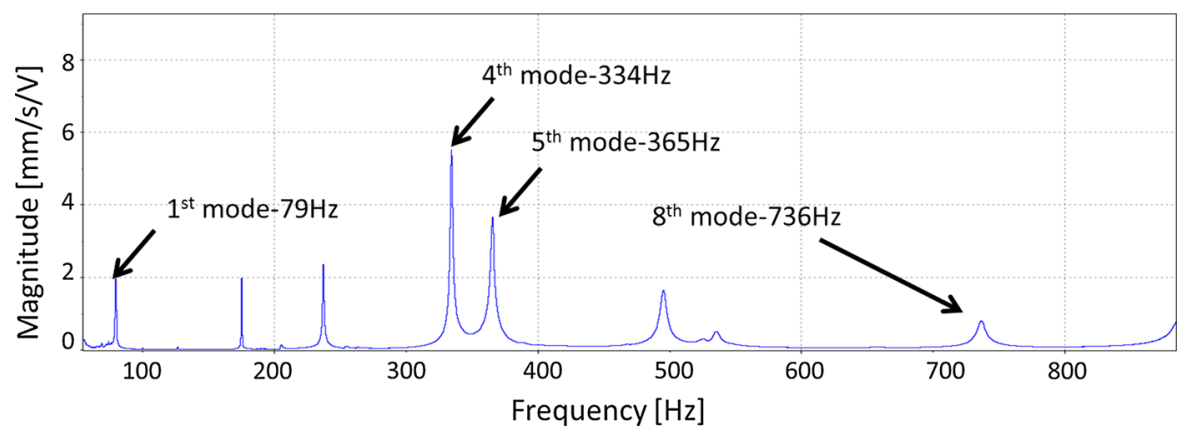

(d)

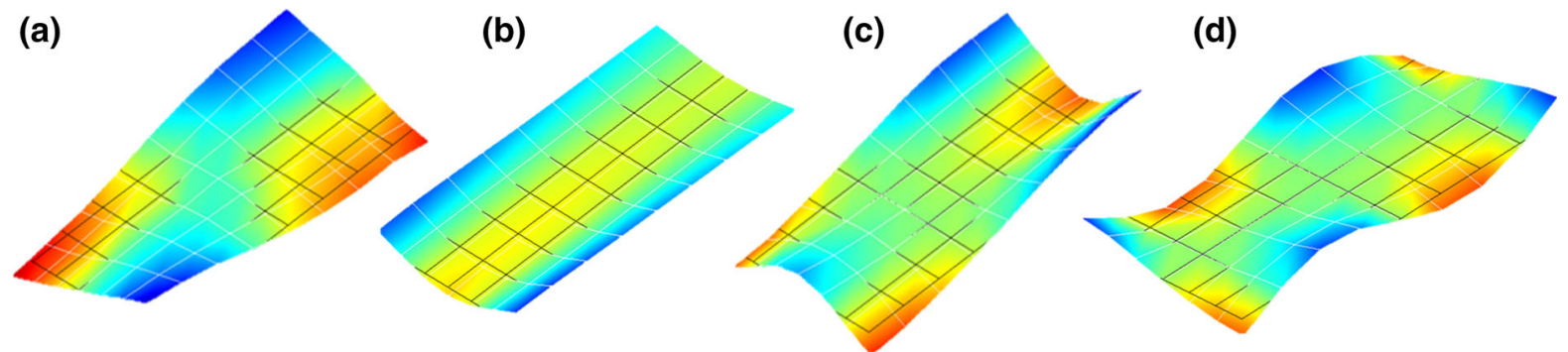

(a)

Fig. 10 Mode shapes selected for nonlinear acoustic tests: a 1 st mode $-79 \mathrm{~Hz}$; b 4 th mode $-334 \mathrm{~Hz}$; c 5 th mode $-365 \mathrm{~Hz}$; d 8 th mode $-736 \mathrm{~Hz}$

- 5th vibration mode $(365 \mathrm{~Hz})$ - the second strongest vibration with the dominant in-plane motion of delaminated plies;

- 8th vibration mode $(736 \mathrm{~Hz})$ - produces the largest level of motion of delaminated plies.

The frequencies of the above selected vibration modes were used in the nonlinear vibration test described in Sect. 6.2.

\subsection{Nonlinear vibration test}

Once the frequencies of excitation were selected, the nonlinear vibration test was performed for the intact (i.e. undamaged) and damaged composite plates. The plates were vibrated using single-point harmonic excitation. The excitation frequency corresponded to the selected frequencies of the selected vibration modes. The test was performed for various levels of excitation amplitude. The excitation signal was generated using a built-in signal generator of the Polytec $P S V-400$ laser vibrometer amplified by an Electronics PAHV 2000 high-voltage amplifier. The excitation was introduced to the plate through a surface-bonded NOLIAC CMAP04 stack actuator. Vibration responses were acquired using a Polytec PSV-400 laser vibrom- eter and data acquisition system. Measurements were taken in 25 symmetrically and equally spaced locations on the plates. Figure 11a shows the experimental setup used for damage detection. The measuring grid is illustrated in Fig. 11b.

\section{Impact damage detection results}

This section presents experimental results form the nonlinear vibration test. Figure 12 gives examples of the response spectra for the undamaged and damaged composite plates. These results-obtained for the eighth vibration mode excitation - display higher harmonics for both plates. However, the amplitude level of odd harmonics for the damaged plate is much larger than the amplitude of other harmonics. Since this vibration mode is relatively weak (see Fig. 8) and the excitation $30 \mathrm{~V}$ amplitude used was relatively small, the fundamental and higher harmonics - that can be observed-are embedded in a significant background noise. The spectra of the response signal contain many additional components that are uncorrelated with the excitation frequency. These additional components in the spectrum can originate from many sources, e.g. inadequacies in the measurement chain, resonance of 
(a)

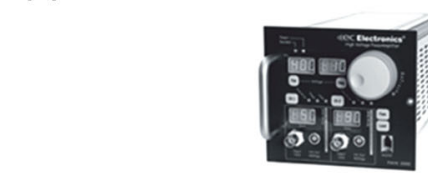

EC Electronics PAHV 2000

NOLIACCMAPO4 stack actuator
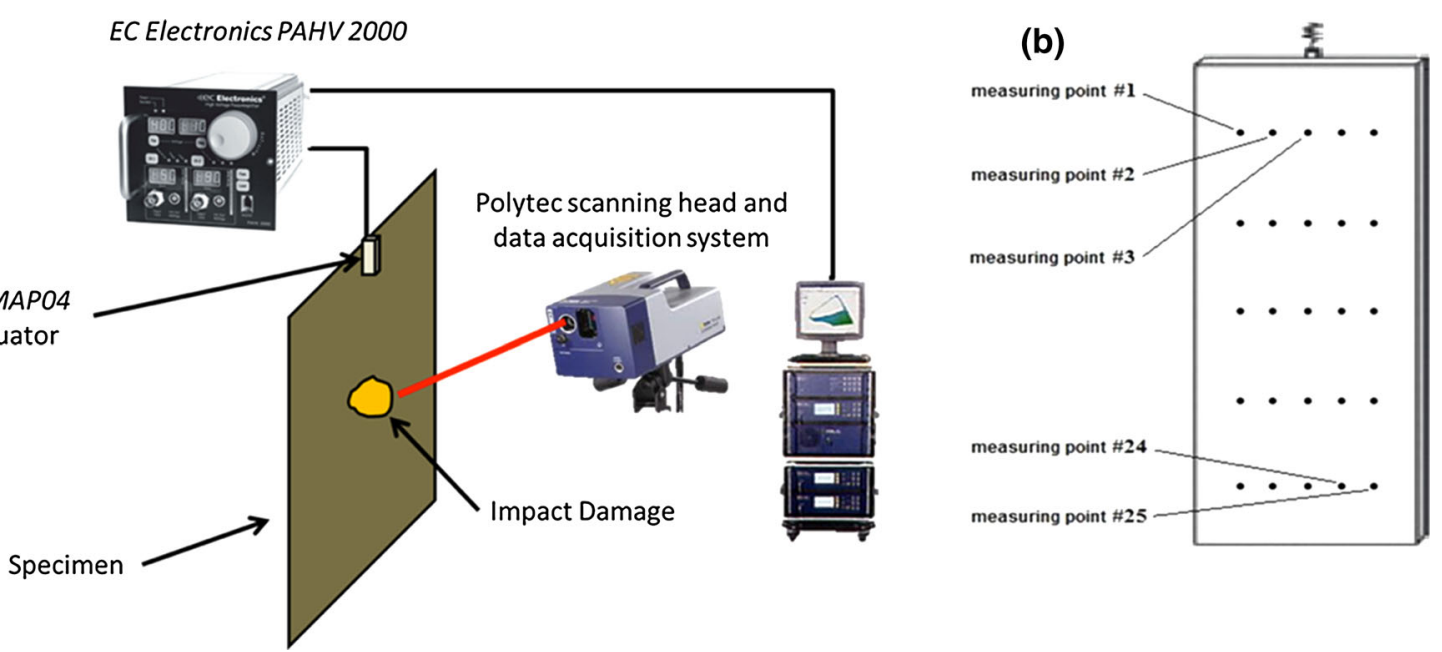

Fig. 11 Experimental arrangements: a experimental set-up; b measuring grid
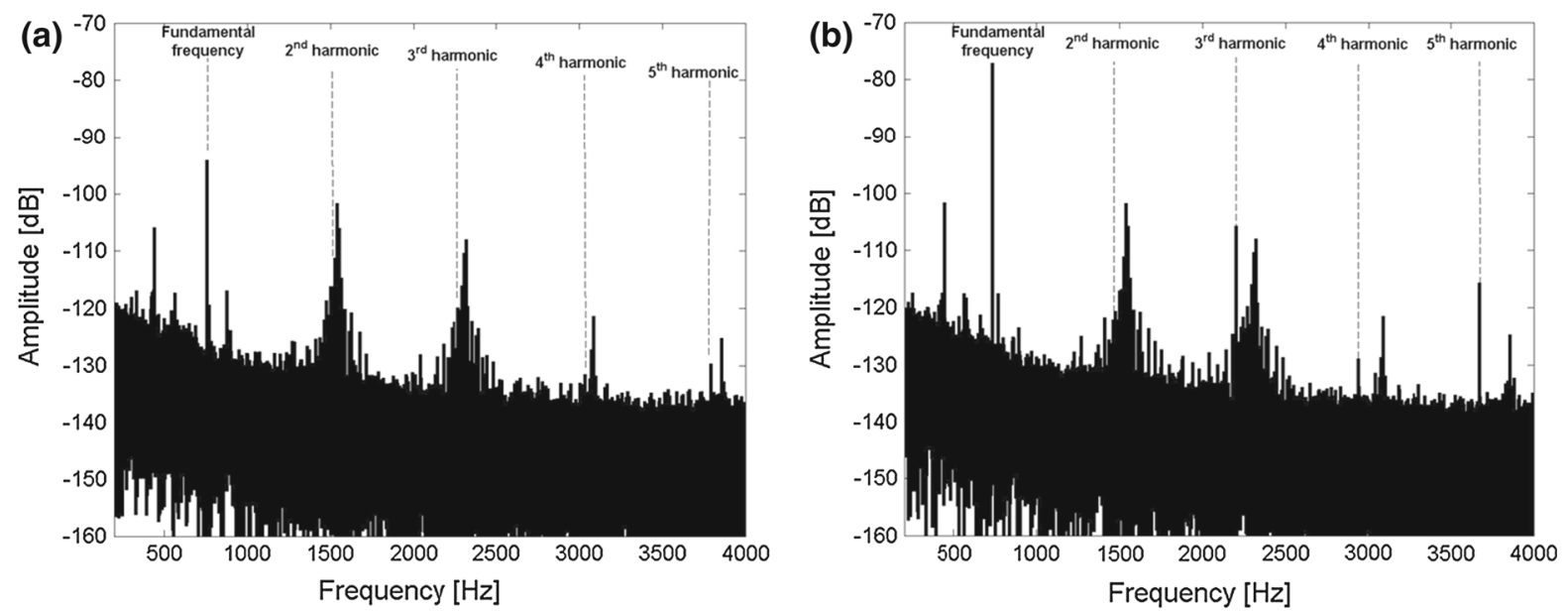

Fig. 12 Examples of response spectra for the eighth vibration mode excitation: a undamaged composite plate; $\mathbf{b}$ damaged composite plate

excitation sources or influence of the boundary conditions.

The mean value of triple correlation coefficient was calculated for vibration response data from all measuring locations. The $20 \mathrm{~s}$ time record of acquired signal was divided into $1 \mathrm{~s}$ segments. The Hamming and rectangular windows were employed as internal and external windows, respectively. To avoid possible leakage of information, the $50 \%$ overlapping between segments was used.

In order to verify the effectiveness and confidence level of the proposed technique, the Fisher criterion was employed. This statistical measure gives information about possible scatter between and within data classes investigated (i.e. the undamaged and damaged conditions investigated). The statistical analysis was based on the mean and variance. The Fisher criterion can be obtained as

$F_{c}=\frac{\left(\mu_{\text {damaged }}-\mu_{\text {undamaged }}\right)^{2}}{\sigma_{\text {damaged }}+\sigma_{\text {undamaged }}}$

where $\mu_{\text {damaged }}$ and $\mu_{\text {undamaged }}$ are the mean data values for the damaged and undamaged plate, respectively, and $\sigma_{\text {damaged }}$ and $\sigma_{\text {undamaged }}$ are data variances for the damaged and undamaged data, respectively. The assumption is that the larger the value of the Fisher criterion, the better the confidence level that the two classes investigated are separated. 
Fig. 13 Triple correlation coefficients and Fisher criterion for damaged and undamaged plates: a first vibration mode; $\mathbf{b}$ fourth vibration mode, $\mathbf{c}$ fifth vibration mode and $\mathbf{d}$ eighth mode. Left column a-d presents the TC coefficient values, and right $\mathbf{e}-\mathbf{h}$ presents the Fisher criterion for successive vibration modes
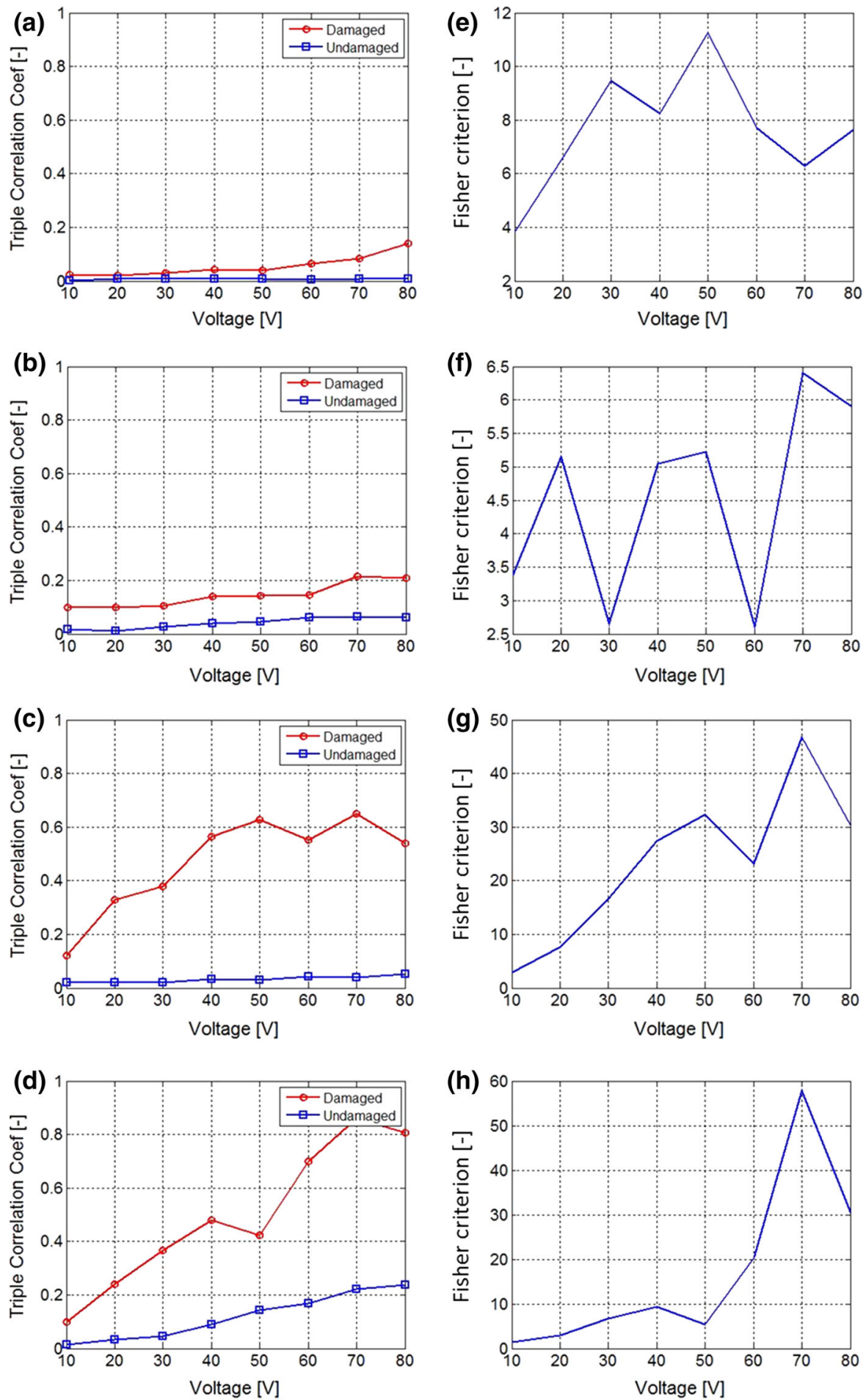

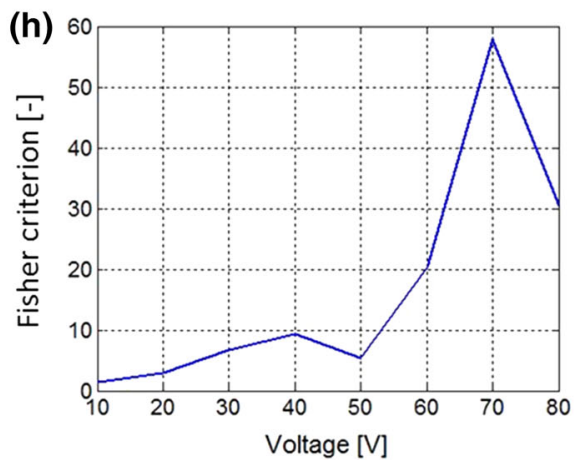

The results are presented in Fig. 13 for all investigated vibration mode excitations. Here, the values of the triple correlation coefficients and the Fisher crite- rion are plotted for both, i.e. the undamaged and damaged, composite plates. When the undamaged plate is excited using the frequency of the first vibration mode 
(Fig. 12a, b), the values of triple correlation are very close to 0 for all excitation amplitude levels.

The same excitation used for the delaminated platethat exhibits very little or virtually no relative movement between delamination plies-leads to monotonically increasing values of the triple correlation for the amplitude excitation levels above 40-50 V. However, the triple correlation values are always smaller than 0.2 , and the corresponding Fisher criterion is relatively small (always smaller than 12).

The excitation of the strongest fourth vibration mode (Fig. 13c, d) separates the triple correlation curves for the undamaged and damaged composite plate quite well. However, the relevant Fisher criterion coefficient is always smaller than 7 for all amplitude excitation levels, giving very little confidence in the results. Also, the values of triple correlation for the undamaged and damaged composite plate are always smaller than 0.1 and 0.21 , respectively, for all analysed excitation amplitudes.

The excitation corresponding to the frequency of the fifth vibration mode (Fig. 13e, f) produces the best damage detection results. The values of triple correlation for the undamaged plate are always smaller than 0.07 for all amplitude levels investigated. The triple correlation increases from the initial value of 0.12 to the maximum value of 0.63 for the excitation amplitude of 10 and $70 \mathrm{~V}$, respectively. Also, the triple correlation curves for the undamaged and damaged composite plate are always well separated, and the relevant values of the Fisher criterion remain relatively large (i.e. larger than 20) when amplitude excitation levels are larger than $35 \mathrm{~V}$. This gives good confidence level in the damage detection results. The largest value 45 of the Fisher criterion coefficient is reached for the excitation amplitude equal to $70 \mathrm{~V}$. It is important to note that similarly to the fourth mode, the fifth mode is one of the two strongest vibration modes investigated. However, in contrast to the fourth mode, the fifth mode is dominated by the in-plane-rather than out-of-plane-motion of delaminated plies.

When the plates are excited using the frequency of the weakest eighth vibration mode (Fig. 13g, h), damage detection results are also very good. The triple correlation curves are well separated for all amplitude excitation levels investigated. The best results are obtained when the plates are excited with amplitudes larger than $60 \mathrm{~V}$. These excitation levels give triple correlation values larger than 0.6 for the damaged plate.
The relevant values of the Fisher criterion are always larger than 20 giving the maximum of 58 for the excitation amplitude equal to $70 \mathrm{~V}$. It is important to recall that this excitation produces the strongest in-plane motion of delaminated planes. Interestingly, when the plate is not damaged, the eighth vibration mode produces the largest (monotonically increasing with excitation amplitude) levels of triple correlation.

\section{Conclusions}

Nonlinear effects in vibration responses were studied for the undamaged composite plate and the composite plate with a delamination. These effects were investigated using the triple correlation. The analysis was focused on higher harmonic generation in vibration responses for three different scenarios associated with the movement of delaminated plies, i.e. no motion, out-of-plane and in-plane motions. Various excitation amplitude levels were used in these investigations.

The results presented show that:

- The selection of excitation frequency is important for the generation of higher harmonics that are associated with delamination. The results show that the strongest vibration mode does not need to lead to the strongest nonlinear effect.

- Movement of delaminated plies enhances nonlinear effects. This behaviour is particularly observed when weaker vibration modes and smaller excitation amplitudes are used.

- The most significant nonlinear effect has been observed for the in-plane motion of the delaminated plies. When delaminated plies produce the out-ofplane motion (or very little motion at all), damagerelated nonlinearities are much weaker. This suggests that the nonlinear mechanism of higher harmonics generation due to damage is associated with dissipation (friction and/or hysteresis) rather than with elasticity.

- When the plate is delaminated, higher amplitude levels of excitation produce stronger nonlinear effects, as expected. However, when the in-plane motion of delaminated plies is involved, even relatively small amplitude excitation levels lead to relatively strong nonlinearities. Interestingly, large excitation amplitudes lead to nonlinear effects in the undamaged composite plate as expected. 
- The strongest nonlinear effect for the undamaged plate has been observed when the plate was excited with the large amplitudes of the eighth vibration mode. This effect needs to be explained and requires further investigations.

The advantage of the presented method-if compared with the techniques described in the references-is the simplicity and confidence in the presented results. A simple vibration test - that involves a surface-bonded piezoceramic element — can be used for experimental analysis. Statistics (the Fisher discriminant) can be obtained to select the level of excitation. This is very important since the majority of nonlinear methods do not provide any guidance with respect to the excitation. It is well known that all engineering system will become eventually nonlinear when excited with large forces. Then it is impossible to decide which amplitude level to use for damage detection and whether the nonlinearity relates to damage or perhaps to material. The proposed method avoids this problem. In addition, the proposed damage index is normalised, so one gets the idea about possible level of nonlinearity (damage).

In summary, the work presented shows that triple correlation can be used effectively not only to reveal nonlinear coupling between the fundamental and higher harmonics, but also to reliably detect relatively small delaminations in impacted composite plates. The work also demonstrates that when the triple correlation is combined with the Fisher criterion analysis, the method can be used to establish the best (or optimal) parameters, i.e. frequencies and amplitudes levels of excitation, leading to more confident damage detection results. Finally, it is also clear that further research modelling and experimental work are required to confirm all the above findings.

Acknowledgments The work presented in this paper was supported by funding from the research Project No. N501158640, sponsored by the Polish National Science Centre.

Open Access This article is distributed under the terms of the Creative Commons Attribution License which permits any use, distribution, and reproduction in any medium, provided the original author(s) and the source are credited.

\section{References}

1. Staszewski, W.J., Boller, C., Tomlinson, G.R.: Health Monitoring of Aerospace Structures. Wiley, Chichester (2003)
2. Staszewski, W.J., Mahzan, S., Traynor, R.: Health monitoring of aerospace composite structures: active and passive approach. Compos. Sci. Technol. 69(11-12), 1678-1685 (2009)

3. Bunsell, A.R.: The monitoring of damage in carbon fibre composite structures by acoustic emission. In: Marshall, I.H. (ed.) Composite Structures 2, pp. 1-20. Springer, Netherlands (1983)

4. Jingpin, J., Bin, W., Cunfu, H.: Acoustic emission source location methods using mode and frequency analysis. Struct. Control Health 15(4), 642-651 (2008)

5. Boller, C., Chang, F.-K., Fujino, Y.: Encyclopedia of Structural Health Monitoring, vol. 5. Wiley, Chichester (2009). Section 2

6. Coverley, P.T., Staszewski, W.J.: Impact damage location in composite structures using optimised sensor triangulation procedure. Smart Mater. Struct. 12(5), 795-803 (2003)

7. LeClerc, J.R., Worden, K., Staszewski, W.J., Haywood, J.: Impact detection in an aircraft composite panel: a neural network approach. J. Sound Vib. 299(3), 672-682 (2007)

8. Pieczonka, Ł., Klepka, A., Staszewski, W.J., Uhl, T., Aymerich, F.: Analysis of vibro-acoustic modulations in nonlinear acoustics used for impact damage detectionnumerical and experimental study. Key Eng. Mater. 558, 341-348 (2013)

9. Klepka, A., Staszewski, W.J., di Maio, D., Scarpa, F.: Impact damage detection in composite chiral sandwich panels using nonlinear vibro-acoustic modulations. Smart Mater. Struct. 22(8), 084011 (2013)

10. Klepka, A., Pieczonka, L., Staszewski, W.J., Aymerich, F.: Impact damage detection in laminated composites by nonlinear vibro-acoustic wave modulations. Compos Part B: Eng. 65, 99-108 (2014)

11. Zou, Y., Tong, L., Steven, G.P.: Vibration-based modeldependent damage (delamination) identification and health monitoring for composite structures: a review". J. Sound Vib. 230, 357-378 (2000)

12. Farrar, C.R., Doebling, S.W., Nix, D.A.: Vibration-based structural damage identification. Philos. Trans. R Soc. A 359, 131-149 (2001)

13. Montalvao, D., Maia, N.M.M., Ribeiro, A.M.R.: A review of vibration-based structural health monitoring with special emphasis on composite materials. Shock Vib. 38(4), 1-6 (2006)

14. Friswell, M.I.: Damage identification using inverse methods. Philos. Trans. R Soc. A 365(1851), 393-410 (2007)

15. Summerscales, J. (ed.): Non-destructive Testing of FibreReinforced Plastic Composites. Elsevier Applied Science, London (1987)

16. Schilling, P.J., Karedla, B.R., Tatiparthi, A.K., Verges, M.A., Herrington, P.D.: X-ray computed microtomography of internal damage in fiber reinforced polymer matrix composites. Compos. Sci.Technol. 65(14), 2071-2078 (2005)

17. Hung, Y.Y.: Applications of digital shearography for testing of composite structures. Compos. B Eng. 30, 765-773 (1999)

18. Pieczonka, L., Szwedo, M.: Vibrothermography. In: Stepinski, T., Uhl, T., Staszewski, W.J. (eds.) Advanced Structural Damage Detection, pp. 251-277. Willey, Chichester (2013)

19. Pieczonka, L., Aymerich, F., Brozek, G., Szwedo, M., Staszewski, W.J., Uhl, T.: Modelling and numerical sim- 
ulations of vibrothermography for impact damage detection in composites structures. Struct. Control Health 20(4), 626638 (2013)

20. Summerscales, J. (ed.): Non-destructive Testing of FibreReinforced Plastic Composites. Elsevier Applied Science, London (1990)

21. Nesvijski, E.G.: Some aspects of ultrasonic testing of composites. Compos. Struct. 48(1), 151-155 (2000)

22. Diamanti, K., Hodgkinson, J.M., Soutis, C.: Detection of low-velocity impact damage in composite plates using Lamb waves. Struct. Health Monit. 3(1), 33-41 (2004)

23. Pavlopoulou, S., Staszewski, W.J., Soutis, C.: Evaluation of instantaneous characteristics of guided ultrasonic waves for structural quality and health monitoring. Struct. Health Monit. 20(6), 937-955 (2013)

24. Balasubramaniam, K.: Lamb-wave-based structural health monitoring technique for inaccessible regions in complex composite structures. Struct. Control Health (2013). doi:10. $1002 /$ stc. 1603

25. Stepinski, T., Uhl, T., Staszewski, W.J.: Advanced Structural Damage Detection. Wiley, Chichester (2013)

26. Mańka, M., Rosiek, M., Martowicz, A., Stepinski, T., Uhl, T.: Lamb wave transducers made of piezoelectric macrofiber composite. Struct. Control Health 20(8), 1138-1158 (2013)

27. Mattei, C., Marty, P.: Imaging of fatigue damage in CFRP composite laminates using nonlinear harmonic generation. In: AIP Conference Proceedings 22, 989 (2003)

28. Pfleiderer, K., Krohn, N., Stoessel, R., Buse, G.: Defectselective imaging by non-linear scanning vibrometry and by non-linear air-coupled ultrasound inspection. NDT E Int. 8(2), 1-7 (2003)

29. Li, W., Cho, Y., Achenbach, J.D.: Detection of thermal fatigue in composites by second harmonic Lamb waves. Smart Mater Struct. 21, 085019 (2012)

30. Li, W., Cho, Y., Ju, T., Choi, H.S., Kim, N., Park, I.: Evaluation of material degradation of composite laminates using nonlinear lamb wave. In: Nondestructive Testing of Materials and Structures, vol. 6, pp. 593-598. RILEM Bookseries (2013)

31. Meo, M.,Zumpano, G.: Nonlinear elastic wave spectroscopy identification of impact damage on a sandwich plate. Compos. Struct. 71(3), 469-474 (2007)

32. Zumpano, G., Meo, M.: Damage localization using transient non-linear elastic wave spectroscopy on composite structures. Int. J. Nonlin. Mech. 43(3), 217-230 (2008)

33. Aymerich, F., Staszewski, W.J.: Impact damage detection in composite laminates using nonlinear acoustics. Compos. Part A Appl. Sci. 41(9), 1084-1092 (2010)

34. Klepka, A.: Nonlinear acoustics. In: Stepinski, T., Uhl, T., Staszewski, W.J. (eds.) Advanced Structural Damage Detection, pp. 73-107. Willey, Chichester (2013)

35. Pieczonka, L., Klepka, A., Staszewski, W.J., Uhl, T., Aymerich, F.: Analysis of vibro-acoustic modulations in nonlinear acoustics used for impact damage detection: numerical and experimental study. Key Eng. Mater. 558, 341-348 (2013)

36. Broda, D., Staszewski, W.J., Martowicz, A., Uhl, T., Silberschmidt, V.V.: Modelling of nonlinear crack-wave interactions for damage detection based on ultrasound: a review. J. Sound Vib. 333, 1097-1118 (2014)
37. Aymerich, F., Staszewski, W.J.: Experimental study of impact-damage detection in composite laminates using a cross-modulation vibro-acoustic technique. Struct. Health Monit. 9(6), 541-553 (2010)

38. Bentahar, M., Marec, A., Guerjouma, R., El, Thomas J.H.: Nonlinear acoustic fast and slow dynamics of damaged composite materials: correlation with acoustic emission. In: Ultrasonics Wave Propagation in Non Homogeneous Media. Springer, Berlin 128, 161-171 (2009)

39. Murphy, K.D., Nichols, J.M.: Modeling and detection of delamination in composite structures. In: Proceedings of the IMAC-XXVII, 9-12 February, Orlando, Florida (2009)

40. Seaver, M., Aktas, E., Trickey, S.T.: Quantitative detection of low energy impact damage in a sandwich composite wing. J. Intell. Mater. Syst. Struct. 21, 297 (2010)

41. Farrar, C., Worden, K., Todd, M.D., Park, G., Nichols, J., Adams, D.E., Bement, M.T., Farinholt, K.: Nonlinear system identification for damage detection, technical report no. LA1453, Los Alamos National Laboratory (2007)

42. Worden, K., Farrar, C.R., Haywood, J., Todd, M.: A review of nonlinear dynamics applications to structural health monitoring. Struct. Control Health 15(4), 540-567 (2008)

43. Sinou J.-J. (2009). A review of damage detection and health monitoring of mechanical systems from changes in the measurement of linear and nonlinear vibrations. In: Sapri, R.C. (eds.), Mechanical Vibrations: Measurement, Effects and Control, pp 643-702

44. Iwaniec, J., Uhl, T., Staszewski, W.J., Klepka, A.: Detection of changes in cracked aluminium plate determinism by recurrence analysis. Nonlinear Dyn. 70(1), 125-140 (2012)

45. Underwood, S.S., Adams, D.E.: Composite damage detection using laser vibrometry with nonlinear response characteristics. In Proceedings of IMAC-XX-VIII, 1-4 February, Jacksonville, Florida, pp 181-187 (2010)

46. Zwink, B.R., Adams, D. E., Evans, R.D., Koester, D.J.: Wide-area damage detection in military composite helicopter structures using vibration-based reciprocity measurements. In: Proceedings of IMAC-XXVII, 9-12 February, Orlando, Florida

47. Zwink, B.R.: Nondestructive evaluation of composite material damage using vibration reciprocity measurements. J. Vib. Acoust. 134(4), 041013 (2012)

48. Oruganti, K., Mehdizadeh, M., John, S., Herszberg, I.: Vibration-based analysis of damage in composites. Mater Forum 33, 496 (2009)

49. Mendrok, K., Uhl, T.: Experimental verification of the damage localization procedure based on modal filtering. Struct. Health Monit. 10(2), 157-171 (2011)

50. Wei, Z., Hu, X., Fan, M., Zhang, J., Bi, D.: NN-based damage detection in multilayer composites. In: Proceedings of ICNC-2005, pp. 592-601 (2005)

51. Ullah, I., Sinha, J.K., Pinkerton, A.: Vibration-based delamination detection in a composite plate. Mech. Adv. Mater. Struct. 20(7), 536-551 (2013)

52. Courtney, C.R.P., Neild, S.A., Wilcox, P.D., Drinkwater, B.W.: Application of the bispectrum for detection of small nonlinearities excited sinusoidally. J. Sound Vib. 329, 42794293 (2010)

53. Bruneau, M., Potel, C.: Materials and Acoustics Handbook. Wiley-ISTE, (2010) 
54. Brush, E., Adams, D.: Development of a dynamic model for subsurface damage in sandwich composite materials. In: Proceedings of IMAC-XXVIII, 1-4 February, pp. 129-136. Jacksonville, Florida (2010)

55. Delsanto, P.P. (ed.): Universality of Nonclassical Nonlinearity. Springer, New York (2007)

56. Chatterjee, A.: Identification of System Nonlinearity Structure by Harmonic Probing. In: Proceedings of the IMACXXVII February 9-12, 2009 Orlando, Florida (2009)

57. Lü, N.C., Cheng, Y.H., Li, X.G., Cheng, J.: Asymmetrical dynamic fracture model of bridging fiber pull-out of unidirectional composite materials. Nonlinear Dyn. 66(1-2), 1-14 (2011)

58. Wright, J.E.: Compound bifurcations in the buckling of a delaminated composite strut. Nonlinear Dyn. 43(1-2), 5972 (2006)

59. Hiwarkar, V.R., Babitsky, V.I., Silberschmidt, V.V.: On the modelling of dynamic structures with discontinuities. Nonlinear Dyn. 67(4), 2651-2669 (2012)

60. Lohmann, A.W., Wirnitzer, B.: Triple correlations. In: Proceedings of IEEE. 72(7), 889-901 (1984)

61. Olsson, Robin: Analytical model for delamination growth during small mass impact on plates. Int. J. Solids Struct. 47(21), 2884-2892 (2010)

62. Fackrell, J.W.A., White, P.R., Hamond, J.K., Pinnington, R.J., Parsons, A.T.: The interpretation of the bispectra of vibration signals: I. Theory. Mech. Syst. Signal Proc. 9(3), 257-266 (1995)

63. Petrunin, I., Gelman, L.: Novel optimisation of bicoherence estimation for fatigue monitoring. Insight 50(3), 133 (2008)
64. Lévai, À.: The Novel Triple Covariance as a Tool for Condition Monitoring, MSc Thesis, supervisor: Gelman L., Cranfield University (2011)

65. Straczkiewicz, M.: Novel technique, the triple correlation based on the chirp-Fourier transform for damage detection, MSc Thesis, Cranfield University, UK., supervisor: Gelman L., Cranfield University, UK (2011)

66. Gelman, L., El, Lapena, Thompson, C.: Advanced higher order spectra for classification of damage in transient conditions. J. Intel. Mater. Syst. Struct. 20, 1343 (2009)

67. Yam, L.H., Wei, Z., Cheng, L., Wong, W.O.: Numerical analysis of multi-layer composite plates with internal delamination. Comput. Struct. 82(7-8), 627-637 (2004)

68. Alnefaie, K.: Finite element modeling of composite plates with internal delamination. Compos. Struct. 90(1), 21-27 (2009)

69. Tsai, S.W.: Strength and life of composites. JEC Composites, (2008)

70. Parlett, Beresford N.: The Symmetric Eigenvalue Problem, vol. 7. Prentice-Hall, Englewood Cliffs (1980)

71. MSC Software Corporation, MSC Nastran 2013 Dynamic Analysis User's Guide, (2013) 